\title{
Multiple prolapsing mullerian vaginal cysts mimicking cystocele and enterocele
}

\author{
Sipra Bagchi ${ }^{1}$, Ashish Kumar Gupta ${ }^{2}$
}

\begin{abstract}
${ }^{1}$ Department of Obstetrics and Gynaecology, ${ }^{2}$ Department of Radiodiagnosis SRMS Institute of Medical Sciences, Bareilly, Uttar Pradesh, India
\end{abstract}

Received: 06 March 2016

Accepted: 04 April 2016

\section{*Correspondence:}

Dr. Sipra Bagchi,

E-mail: drsiprabagchi@gmail.com

Copyright: () the author(s), publisher and licensee Medip Academy. This is an open-access article distributed under the terms of the Creative Commons Attribution Non-Commercial License, which permits unrestricted non-commercial use, distribution, and reproduction in any medium, provided the original work is properly cited.

\begin{abstract}
Multiple vaginal cysts are rare. Large cysts may present as vaginal wall prolapse. Proper assessment by clinical examination (under anaesthesia if necessary) and by USG and/or MRI should be done before surgical planning. Complete excision of cyst wall is necessary to prevent recurrence. A 40 years old P1L1 presented with mass per vaginum associated with pain and dyspareunia. On examination third degree cystocoele and a large posterior vaginal wall cyst with enterocoele was seen. Ultrasonography revealed no remarkable finding. Examination under anaesthesia followed by cyst excision was planned. Preoperatively three cysts were found, one on anterior wall mimicking as cystocoele, two cysts over prolapsed posterior vaginal wall, of which one had already ruptured. All the three cysts were excised completely. Histopathology revealed Mullerian cyst. This was an unusual case of multiple Mullerian vaginal cysts.
\end{abstract}

Keywords: Multiple vaginal cysts, Mullerian, Cystocoele, Enterocoele

\section{INTRODUCTION}

Vaginal cystic lesions are relatively uncommon and asymptomatic in most of the cases. These vaginal cysts can be classified according to histology of their lining epithelium into mullerian cysts, Epidermal inclusion cyst, bartholin duct cyst, Gartner duct cyst, endometroid cyst and other unclassified variety. ${ }^{1,2}$ Of these mullerian cyst being the most common constitutes $30 \%$, bartholin duct cyst $27.5 \%$, Epidermal inclusion cyst $25 \%$ and remaining $17.5 \%$ is constituted by Gartner duct cyst, endometroid cyst and unclassified type. ${ }^{1-3}$ The mullerian cysts are usually small, ranging from 0.1 to $2 \mathrm{~cm}$ in size, rarely they may reach $>4 \mathrm{~cm}$ in diameter. These cysts are usually asymptomatic but in symptomatic cases there may be a visible or palpable mass, dyspareunia, voiding problem, vaginal discharge and sometimes protruding mass with pain. ${ }^{4,5}$ We present a rare case of multiple vaginal cysts involving the anterior and posterior vaginal walls mimicking as cystocele and enterocoele respectively.

\section{CASE REPORT}

A 40 years old P1L1 female presented to the outpatient department with complaints of mass protruding out of vagina for 1 year. The size of the mass had increased in size in last 5-6 months and was associated with pain and dyspareunia. She also gave history of sudden decrease in size of the mass followed by mucoid discharge per vaginum 1 month back. There was no history of any menstrual abnormality and bladder or bowel problem. Medical history was unremarkable.

Her general and systemic examination was within normal limits. On local examination, there was protrusion of anterior vaginal wall with overlying hyper pigmented patches. A cystic mass of around $5 \times 5 \mathrm{~cm}$ was protruding along with posterior vaginal wall from the posterior fornix. There was an opening poster laterally over the posterior mass through which a probe could be introduced up to $5 \mathrm{~cm}$. The cervical lips could not be 
appreciated and there was no rectocele. Bimanual examination could not be done because of tenderness.

Transabdominal ultrasonography of pelvis showed a normal size uterus and a unilocular cyst of $4 \times 4 \mathrm{~cm}$ in right ovary. A provisional diagnosis of posterior vaginal cyst with cystocoele and ? Enterocoele was made. Examination under aneasthesia followed by cyst excision was planned.
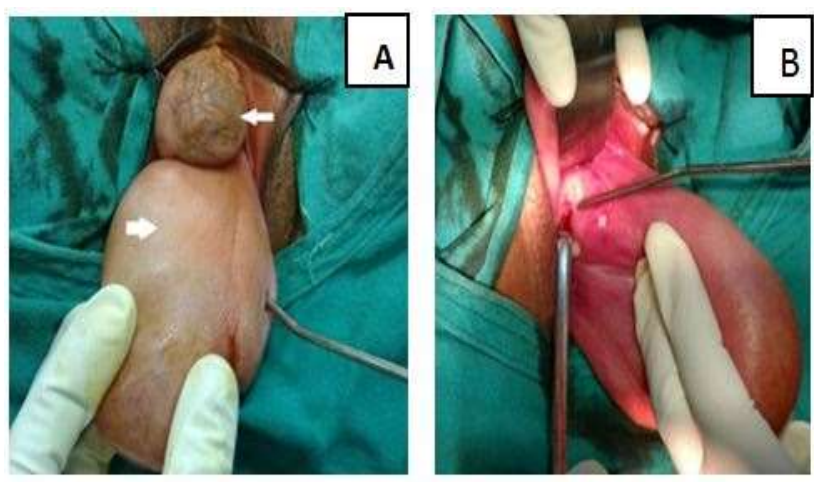

Figure 1: (A) Anterior wall cyst mimicking as cystocoele (thin arrow), posterior large vaginal cyst (thick arrow) with ruptured cyst -opening shown by a probe, (B) cervix shown by a probe.
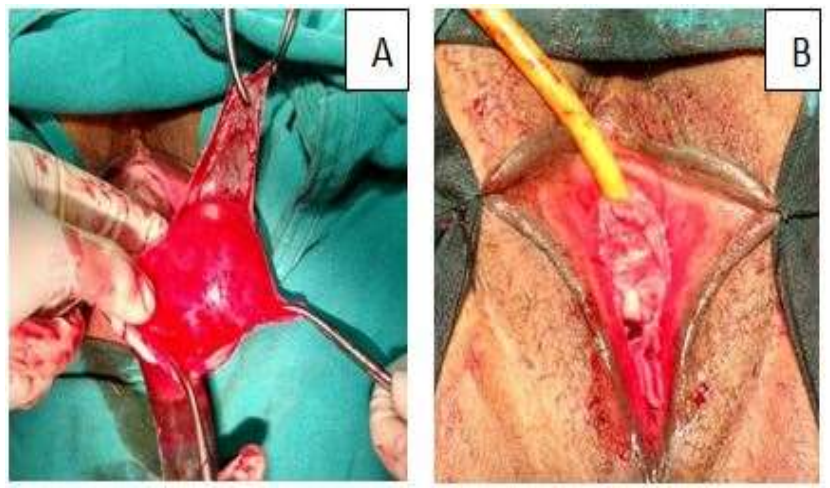

Figure: 2 (A) Cyst excision in progress, (B) post cysts excision and vaginal repair.

Under aneasthesia, it was revealed that the cystocoele was actually an anterior vaginal wall cyst. Cervix could be seen deep between the two protruding masses and was apparently healthy [Figure 1(B)]. There was a large protruding cyst of $10 \times 4 \mathrm{~cm}$ size on post vaginal wall along with a ruptured cyst with the opening situated poster laterally over the protruded mass [Figure 1(A)]. The large posterior cyst was extending deeply and was excised in to by sharp and blunt dissection followed by the excision of the cyst wall of the ruptured poster lateral cyst [Figure 2(A)]. Anterior wall cyst was also extending deeply and got ruptured during excision and purulent material came out. The anterior cyst was approximately $6 \times 4 \mathrm{~cm}$ in size. Redundant vaginal wall was excised followed by repair with delayed absorbable suture after achieving adequate haemostasis [Figure 2 (B)].
Postoperative period was uneventful. Patient was discharged on $4^{\text {th }}$ postoperative day. On histopathology cysts wall were lined by mucin producing columnar epithelial cells which is characteristic of mullerian cyst. The walls were infiltrated with inflammatory cells comprising of lymphocytes and plasma cells. She was followed at 2 weeks and 6 weeks and was doing well with no recurrence.

\section{DISCUSSION}

Vaginal cysts are rare with an estimated prevalence of $<1 \%$. $^{5}$ They predominantly present in women of reproductive age in the third or fourth decade of life and also in children and postmenopausal women. ${ }^{1-5}$ Müllerian cysts, the most common type originate from mullerian epithelial tissue that can persist anywhere in the vaginal wall during replacement of mullerian epithelium with squamous epithelium of the urogenital sinus. ${ }^{5}$ The cysts can thus form at any site within the vaginal walls. However, the anterolateral aspect of the vagina is the most common location for these cysts. ${ }^{5}$ The cysts are usually single but rarely may be multifocal as in our case. The majority of cysts are asymptomatic and rarely require treatment. The large cysts may be mistaken for cystocele, enterocoele, rectocele or a urethral diverticulum., ${ }^{1,2,5}$ Vaginal wall prolapse can be differentiated from a cyst by valsalva's maneuver. Vaginal wall prolapse shows an expansile impulse; while a cyst does not do so. ${ }^{6}$ In our case we could not do this test because of tenderness. Imaging modalities like USG and MRI are helpful in exact localization, number of cysts and communication with the surrounding structures. MRI is superior modality. As the patient was not affordable for MRI, we proceeded for examination under anaesthesia followed by surgery. Histochemical evaluation of epithelial mucin production can differentiate between mullerian and gartner's duct cyst. Epithelium of gartner's cysts is devoid of cytoplasmic mucicarmine and PAS-positive material. ${ }^{1,4,5}$ Symptomatic and/or large vaginal cysts are treated via excision. Removal of entire cyst wall is must to prevent recurrence. However, occasionally, large cysts may extend cranially into the broad ligament, along the entire length of the vagina (via the cervix). Removal of the entire cyst wall in such cases becomes difficult and sometimes impossible. In such cases, if cyst is not completely resected, the interior of the cyst wall should be vaporised to decrease the chances of recurrence. ${ }^{5}$ Malignant change in mullerian cyst is very rare. Till date only one case of adenocarcinoma arising in a vaginal mullerian cyst in a 48 year old woman was reported by Kyung et al. ${ }^{7}$ So the careful follow-up of these patients is necessary, considering the possibility of malignant transformation.

\section{Funding: No funding sources \\ Conflict of interest: None declared \\ Ethical approval: Not required}




\section{REFERENCES}

1. Unnisa S, Rao SB, Rasquinha VC, Prathashwini RK. Unusual case of posterior vaginal wall cyst. IJBAR. 2013;4:3.

2. Samal S, Mahapatro A, Poorkodi B. Posterior vaginal wall cyst of Mullerian origin: a case report. Int J Reprod Contracept Obstet Gynecol. 2015;4(1):245-6.

3. Jayaprakash S, Lakshmidevi M, Kumar GS. A rare case of posterior vaginal wall cyst. BMJ Case Rep. 2011;201:bcr0220113804.
4. Valecha SM, Shah N, Gandhewar M, Shende P. Rare case of prolapsing vaginal cyst. J South Asian Feder Obst Gynae. 2013;5(1):40-1.

5. Töz E, Sanc JM, Cumurcu S, Özcan A. Müllerian Cyst of the Vagina Masquerading as a Cystocele: hindawi publishing corporation: case reports in Obstetrics and Gynecology. 2015;376834:3.

6. Parulekar SV. Vaginal sinus due to rupture of posterior vaginal wall cyst. JPGO. 2015;2:6.

7. Lee KS, Park KH, Lee S, Kim JY, Seo SS. Adenocarcinoma arising in a vaginal mullerian cyst: a case report. Gynaecol Oncol. 2005;99:767-9.

Cite this article as: Bagchi S, Gupta AK. Multiple prolapsing mullerian vaginal cysts mimicking cystocele and enterocele. Int J Reprod Contracept Obstet Gynecol 2016;5:1666-8. 